\title{
Steady State Model of Cooling Tower Used in Air Conditioning
}

\author{
Long Jianyou \\ Shunde Polytechnic College, Shunde, China \\ jianyoulong@163.com
}

\begin{abstract}
To predict the performance of cooling tower used in air conditionings in variable operating conditions, a steady state model of cooling tower suitable for variable conditions simulation was built and tested. Comparison between the prediction value and the experimental value shows good agreement. The results show that this model is suitable for calculation of cooling capacity of cooling tower used in air conditionings at variable inlet temperature or mass flow rate of condensing water, and at variable inlet wet-bulb temperature or mass flow rate of cooling-air. This model is useful for simplifying performance test, equipment selection and running control.
\end{abstract}

Keywords-Cooling tower; Variable operating conditions ; Steady state simulation; Model

\section{INTRODUCTION}

Before the establishment of the simulation model, the actual problem should be simplified and the mathematical model, established. The internal heat and mass transfer process of the air conditioning system using cooling towers is very complicated. Merkel was the first to elaborate the operation mechanism of the air conditioning cooling tower [1], and this mechanism became the theoretical foundation for most people to analyze the cooling tower operation. Merkel's analysis neglected the moisture evaporation, assumed the Lewis number, and made sure the exit state through the cycle numerical integration of two difference equations. Whiller elaborated another method, which derived the relation of the relevant characteristic parameters [2], but this method is of not much value to the engineering design. Sutherland had a strict derivation of the heat and mass transfer process of the cooling tower [3], abandoning Merkel's hypothesis. His calculation results were 5\% - 15\% lower than Merkel's. Jaber and Webb proposed the use of heat transfer unit number method to study the cooling tower [4]. Braun et al worked out a more comprehensive formula based on this research [5]. The research above took into account the heat transfer and mass transfer process insider the tower. Their models are very complicated, and the calculation study is very hard. This paper simplifies the air conditioning cooling tower into the heat exchanger. Based on Merkel's enthalpy difference theory and combined with the heat transfer-unit number method, it uses the Matlab/simulink to establish the air conditioning cooling tower steady state model in the variable working conditions, and verifies the correctness of the model through the factory's actual measurement of the data collected from the variable working conditions of the air conditioning cooling tower.

\section{ESTABLISHING THE AIR CONDITIONING COOLING TOWER MODEL BY ADOPTING THE HEAT TRANSFER UNIT NUMBER METHOD}

To facilitate the simulation calculation, the mathematical model of the air conditioning cooling tower needs to be simplified, assuming:

1) The environment wet air is ideal;

2) The loss of water in evaporation is neglected, the water flow of the air conditioning cooling tower at the inlet and outlet is equal, etc.;

3) The heat and mass transfer coefficient value Lewis is equal to 1 .

On the basis of the above hypothesis, the air conditioning cooling tower can be simplified into the heat exchanger.The product $\mathrm{kA}$ of the heat transfer coefficient $\mathrm{k}$ of the heat exchanger and the heat transfer area $\mathrm{A}$ (the total heat transfer coefficient) is regarded as a parameter, neglecting the internal complicated heat and mass transfer process of the air conditioning cooling tower and adopting the heat transfer unit number mothod in heat exchanger design method to establish air conditioning cooling tower steady state simulation model.

The actual heat transfer effect of the heat exchanger and the most possible effect of the ratio of heat transfer performance $\mathcal{E}$ (effectiveness of heat exchanger) can be represented as:

$$
\varepsilon=\frac{\left(t^{\prime}-t^{\prime \prime}\right) \max }{t_{1}^{\prime}-t_{2}^{\prime}}
$$

In the equation, the common denominator is the possible maximum temperature difference value between the cold and hot fluid in the heat exchanger, and the molecular is the higher one of the actual temperature difference values of the cold or hot fluid in the heat exchanger. When the current is adverse, the efficiency $\mathcal{E}$ of the heat exchanger is:

$$
\varepsilon=\frac{1-\exp [-N T U(1-\omega)]}{1-\omega \exp [-N T U(1-\omega)]}
$$

In the equation, $\omega$ is the ratio between the minimum and maximum of heat capacity in the heat exchanger $\omega=C_{\min } / C_{\max } ; C_{\max }=\max \left(C_{\text {water, }} C_{\text {air }}\right)$, $\mathrm{W} / \mathrm{K} ; C_{\min }=\min \left(C_{\text {water }} C_{\text {air }}\right), \mathrm{W} / \mathrm{K}$. The heat transfer 
unit number NTU (number of transfer unit) indicating the capacity of heat transfer of the heat exchanger can be represented as: $N T U=\frac{k A}{\left(C_{\text {min }}\right)}$

The cooling capacity of the air conditioning cooling tower can be calculated with the following equation:

$$
Q_{\text {water-air }}=\varepsilon C_{\text {min }}\left(T_{\text {in,water }}-T_{\text {in,air }}\right)
$$

The wet bulb temperature of the air flowing out of the air conditioning cooling tower can be calculated with the following equation:

$$
T_{\text {out }, \text { air }}=T_{\text {in,air }}+\frac{Q_{\text {water-air }}}{C_{\text {air }}}
$$

In the equation, $C_{a i r}$ is the wet air heat capacity of the air conditioning cooling tower.

The temperature of the water flowing out of the air conditioning cooling tower water can be calculated with the following equation:

$$
T_{\text {out }, \text { water }}=T_{\text {in,water }}-\frac{Q_{\text {water-air }}}{C_{\text {water }}}
$$

In the equation, $C_{\text {water }}$ is the heat capacity of the water flowing into the air conditioning cooling tower.

Since the wet bulb temperature on the enthalpy wet drawing of wet air and enthalpy value are close to the linear relationship, so the relationship between the enthalpy of wet air and the wet bulb temperature can be represented as:

$$
h=A_{3} t_{\text {web,air }}{ }^{3}+A_{2} t_{\text {web,air }}{ }^{2}+A_{1} t_{\text {web,air }}+A_{0}
$$

In the equation, $h$ is the enthalpy of wet air, $\mathrm{kJ} /(\mathrm{kg} \cdot \mathrm{K})$; $t_{\text {web,air }}$ is the wet bulb temperature of wet air, ${ }^{\circ} \mathrm{C}$.

\section{SiMULATION OF THE AIR CONDITIONING COOLING TOWER}

According to equations (3) to (6), taking the four parameters of the condensation water inlet temperature, the condensation water flow, the cooling air inlet wet bulb temperature and the flow as the input parameters of the model and the cooling capacity of the cooling tower, the air outlet wet bulb temperature and the cooling water outlet temperature as the output parameters of the model, the steady state simulation model of the air conditioning cooling tower can be established, using matlab/simulink, as is shown in Figure 1.

\section{SIMULATION MODEL TEST OF THE AIR CONDITIONING COOLING TOWER}

In order to verify the correctness of the simulation model, this paper simulated the cooling tower of a manufacturer, and the simulation results and the sample data [6] are compared, as is shown in Table 1. From the table, it can be seen that the simulation values of the cooling capacity of the air conditioning cooling tower calculated with the model are in good agreement with the sample values, and the errorrange is within $0.12 \sim 0.15$, which verifies the correctness of the model.

\section{A. Influence of the size of water on the cooling capacity of Tower BNB2-800}

As is shown in Figure 2, with the increase of water, the cooling capacity $\boldsymbol{Q}_{\text {water-air }}$ increases, but the tendency of increase slows, which conforms to the rules. As is shown in Figure 3, with the decrease of the water, the oultlet water temperature $\boldsymbol{t}_{\text {out-water }}$ tends to increase to $28{ }^{\circ} \mathrm{C}$, indicating that when the heat transfer is very good (the size of water is small or the area of heat transfer is very large), the water can only be close to the environment dry bulb temperature $28{ }^{\circ} \mathrm{C}$, which is in line with the heat transfer law. With the decrease of the size of water (the size of heat transfer decreases), and

the air flow remains steady, the outlet air wet bulb temperature $\boldsymbol{t}_{\text {out-air }}$ is close to $28^{\circ} \mathrm{C}$ (namely, equal to the inlet air wet bulb temperature), which is in line with the heat transfer law; With the increase of the size of water (the size of heat transfer increases), and the air flow remains steady, the outlet air wet bulb temperature $\boldsymbol{t}_{\text {out-air }}$ tends to increase to $28^{\circ} \mathrm{C}$ (namely, equal to the inlet water temperature), which is in line with the heat transfer law.

\section{$B$ Influence of the size of air on the cooling capacity of Tower BNB2-800}

As is shown in Figure 4, with the increase of the size of air, the cooling capacity $\boldsymbol{Q}_{\text {water-air }}$ increases, but the tendency of increase slows. As is shown in Figure 5, along with the decrease of the size of air (the size of heat transfer decreases), the outlet water temperature $\boldsymbol{t}_{\text {out-water }}$ tends to increase to $38{ }^{\circ} \mathrm{C}$ (namely, equal to the inlet water temperature), which in line with the heat transfer law. With the decrease of the size of air, and the size of water remains steady, the inlet wind wet bulb temperature $\boldsymbol{t}_{\text {out-air }}$ tends to increase to $38^{\circ} \mathrm{C}$ (namely, equal to the inlet water temperature), which is in line with the heat transfer law.

\section{CONCLUSION}

In conclusion, air conditioning cooling tower is simplified into heat exchanger, which combines with efficacy, heat transfer unit number method and applies Matlab/simulink to establish air conditioning cooling tower model suitable for varied conditions simulation. Therefore, cooling capacity of cooling tower, outlet air wet bulb temperature and outlet cooling water temperature can be calculated in simulation while the parameters of outlet chilled water temperature, chilled water flow, inlet cooling air wet bulb temperature and flow change.

\section{REFERENCES}

[1] Merkel F. Ver dun stung kuh lung [R]. VDIFor schung sarbeiten, No 3275, Berlin, 1925 
[2] Whiller A. A fresh lo ok at the calculation of performance of cooling tower s [G]. ASHRAE Trans, 1976, 82(1)

[3] Sutherland J W. Analysis of mechanical draught counter flow air/ water cooling towers[J]. Journal of $\mathrm{H}$ eat Transfer, 1983, 105 (1): 576-583

[4] Jaber W. Design o f coo ling tower s by the effectiveness NTU method [C]. ASME Winter Annual Meeting. Boston, 1989, 111(4): 837-843
[5] Braun J E, Klein S A, Beckman W A, et al. Methodologies for optimal control of chilled water systems without storage [G].ASHRAE Trans, 1989, 95(1): 652-662

[6] Yin YD, Zhang L, Lan Li etc. Stable state simulation of the counterflow cooling towers used in air conditionings [J]. Refrigeration Air Conditioning and Electric Power Machinery, 2005, 102(2): 11-14

TABLE I. COMPARISON BETWEEN THE COOLING CAPACITY OF THE SIMULATION RESULTS AND THE SAMPLE VALUES

\begin{tabular}{|c|c|c|c|c|c|c|c|}
\hline \multirow{2}{*}{$\begin{array}{l}\text { Type of } \\
\text { tower }\end{array}$} & \multirow{2}{*}{$\begin{array}{c}\text { Size of } \\
\text { circulating } \\
\text { water }(\mathrm{m} 3 / \mathrm{h})\end{array}$} & \multirow{2}{*}{$\begin{array}{c}\text { Size of } \\
\text { air×104 } \\
(\mathrm{m} 3 / \mathrm{h})\end{array}$} & \multicolumn{3}{|c|}{ Cooling capacity $\left(10^{4} \mathrm{~kJ} / \mathrm{h}\right)$} & \multirow{2}{*}{$\begin{array}{l}\text { Inflowing water } \\
\text { temperature }(\mathrm{K})\end{array}$} & \multirow{2}{*}{$\begin{array}{l}\text { Outflowing water } \\
\text { temperature (K) }\end{array}$} \\
\hline & & & $\begin{array}{l}\text { Sample } \\
\text { value }\end{array}$ & $\begin{array}{c}\text { Simulation } \\
\text { value }\end{array}$ & $\begin{array}{c}\text { Error range } \\
(\%)\end{array}$ & & \\
\hline BNB2-008 & 8 & 0.47 & 20.064 & 20.078 & -0.07 & 311.15 & 305.154 \\
\hline BNB2-300 & 300 & 17.5 & 752.4 & 751.284 & 0.15 & 311.15 & 305.167 \\
\hline BNB2-800 & 800 & 40 & 2006 & 2008.404 & -0.12 & 311.15 & 305.152 \\
\hline
\end{tabular}

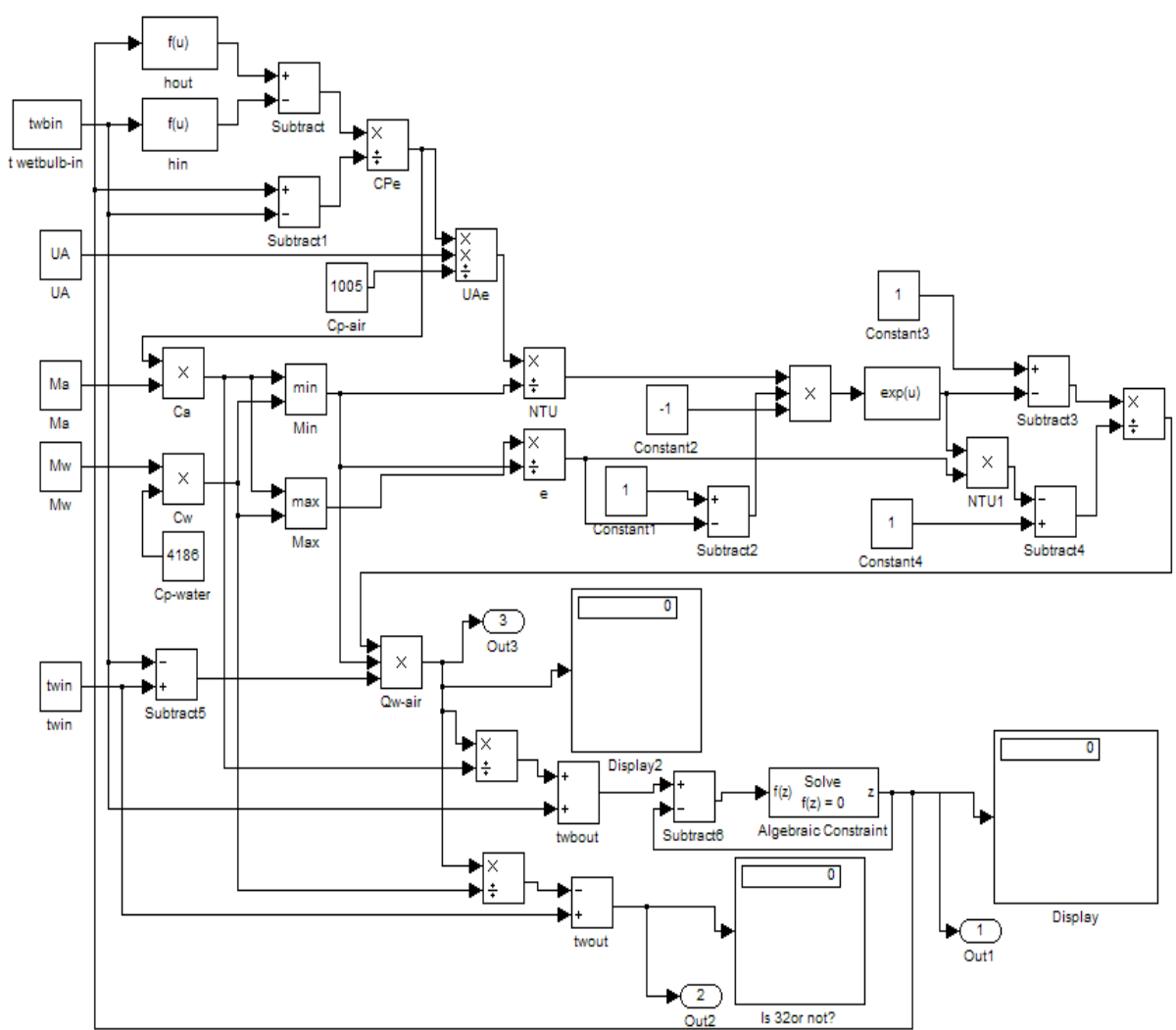

Figure 1. Simulation program of the cooling tower based on matlab/simulink 

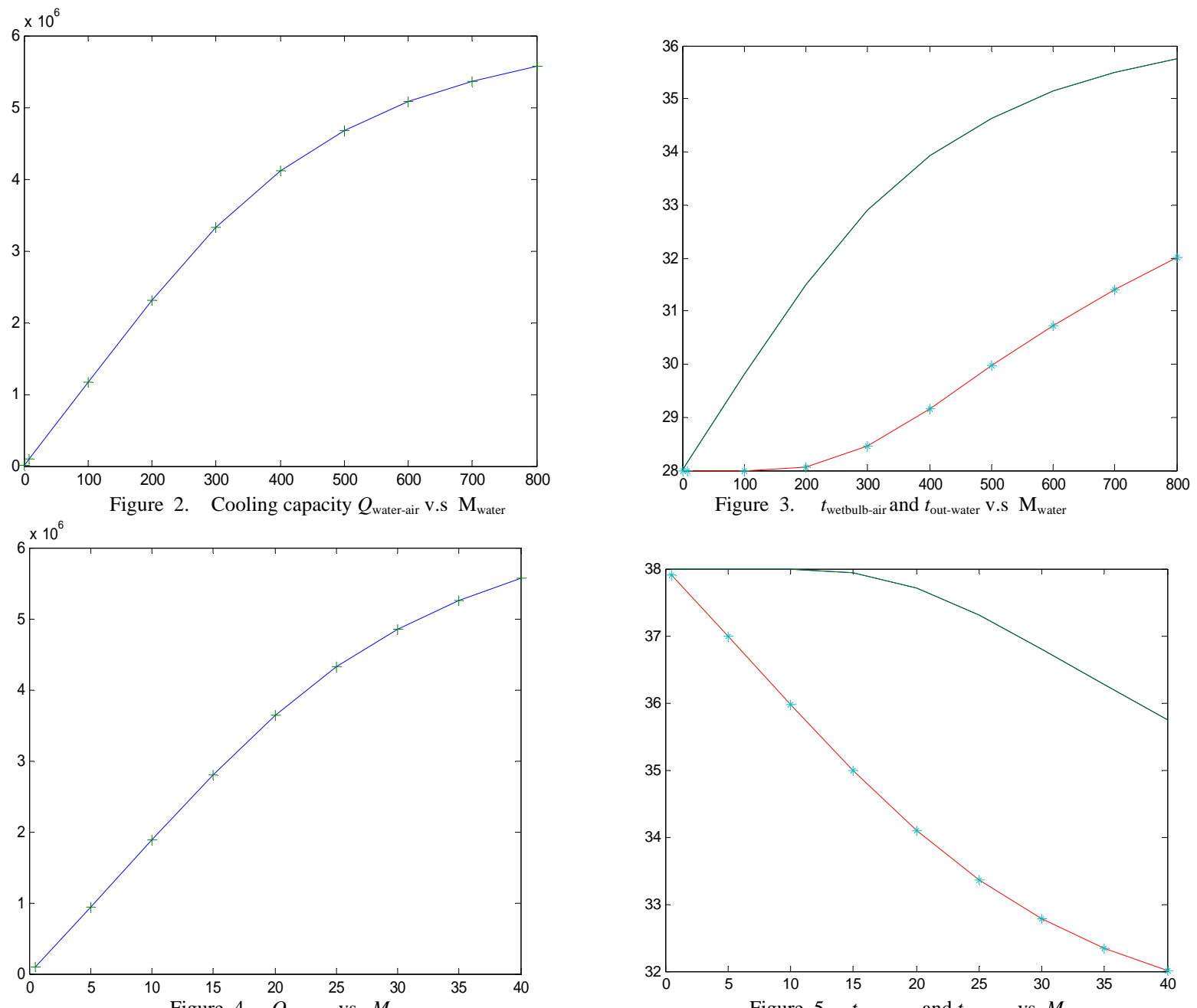

$\begin{array}{ccc}15 & 20 & 25 \\ \text { Figure } & 4 . & Q_{\text {water-air }} \text { Vs. } M_{\text {water }}\end{array}$

Figure 5. $t_{\text {wetbulb-air }}$ and $t_{\text {out-water }}$ vs. $M_{\text {air }}$ 